\title{
Human Myiasis in Abandoned Elderlies of the Niger Delta and South-East Nigeria: Dermatological Implications
}

\author{
Ogbalu, O.K ${ }^{1}$, Bob Manuel, R. B ${ }^{2}$, Eze, C. $\mathbf{N}^{3}$ \\ ${ }^{1}$ Entomology Unit, Department of Applied and Environmental Biology, Rivers State University of Science and Technology, P. M. B, Nigeria \\ ${ }^{2}$ Department of Biology, Ignatius Ajuru University of Education, Rumuolumeni, Port Harcourt, Nigeria \\ ${ }^{3}$ Parasitology Unit, Department of Animal and Environmental Biology, University of Port Harcourt, Choba, Port Harcourt, Nigeria
}

*Corresponding author: Ogbalu, O.K, Entomology Unit, Department of Applied and Environmental Biology, Rivers State University of Science and Technology, P. M. B. 5080 Port Harcourt, Nigeria, E-mail: ogbaluo@yahoo.com

\begin{abstract}
This paper reports for the first time the findings of human myiasis in abandoned elderlies in the Niger Delta and South-east Nigeria. Most myiasis-causing agents recovered from different parts of the elderlies' bodies were Cordylobia anthropophaga, Lucilia sericata, Musca domestica, Chrysomia sp and Sarcophaga vilosa. Parts of the body of the abandoned elderlies from where recoveries of dipterous larvae were made are presented. We assessed the infection rates of abandoned elderlies of the two ecological zones in Nigeria [Niger Delta and South-East]. We studied a cohort of 5 - 10 patients presenting different cases of myiasis in elderlies within the age bracket 68 - 92 years. We extracted maggots from different parts of their bodies. Dermatological data showed variations in infection rates of dipteran larval distributions in the abandoned elderlies of Ogbaru Town in South-east; prominent among them were C. anthropophaga 46\% [CI 24.5 - 46.3]; Chrysomia sp 27\% [CI 95\%, 18.3 - 27.3]; L. serricata 20\% [CI 95\%17.5 - 20.6] and Sarcophaga vilosa, 7\% [CI 5.3 - 7.4]. Overall infection rates in abandoned females in Ughelli for the respective dipteran larvae were for C. anthropophaga 40\% [CI 95\%,36.7 - 44.6]; L. sericata, 29\% [CI 95\%, 27.5 - 30.3]; Chrysomia sp 22\% [C I 95\%, 20.5 - 22.8]; S. vilosa $9 \%$ [CI 95\%, $8.7-9.8]$.
\end{abstract}

Received date: April 26, 2016

Accepted date: May 10, 2016

Published date: May 14, 2016

Citation: Ogbalu, O.K., et al. Human Myiasis in Abandoned Elderlies of the Niger Delta and South-East Nigeria: Dermatological Implications. (2016) Invest Dermatol Venerol Res 2(2): 6773.

DOI: $10.15436 / 2381-0858.16 .885$

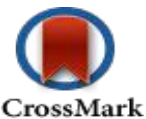

Keywords: Abandoned elderlies; Myiasis; Dermatological implications; Niger delta; South east; Nigeria

\section{Introduction}

Myiasis is a parasitic infestation caused by the larvae of several species of dipteran hexapods in vertebrate organs and tissues. The infestations reduce host physiological functions; destroy host tissues, and cause significant economic losses especially in animals. It is a very rare disease in USA and Europe; however it is becoming increasingly common in the humid zones of Nigeria and other tropical and subtropical countries in persons with poor personal hygiene. Diagnosis and treatment are simple.

Myiasis which is defined as the invasion of the Vertebrate organs and tissues by dipterous larvae has become a neglected infection of the tropics particularly in the humid Niger Delta where it has been reported in newborns, children, adults and also in domestic animals too including dogs, guinea pigs, pigs and cats ${ }^{[1-3]}$. The word diptera represents a large order of insects that possesses a single pair of wings [in Greek, the word diptera implies; di = two, pteron = wing], members also have a non-functional pair which are reduced into organs that serve as balancers during flight. It has been reported to affect neonates and infants that have the afore mentioned animals as pets ${ }^{[4]}$. It has also been reported in breasts and vulvar of some rural nursing mothers ${ }^{[1,3]}$. In most countries of tropical Africa, cases of myiasis do occur but have been not reported as they might have been mis-identified as boils. In most rural settings of Nigeria, natives do not seek medical care and on their own would opt to add oil on the furuncle and press the larvae out. In most cases of unhygienic situations and practices infection rates by the myiasis-causing flies have increased. Their breeding sites 
include refuse dumps, fishing ports, piggeries, carcasses of animals, public latrines, poultry droppings with its high moisture content and slaughter houses etc.

Cases of oral myiasis ${ }^{[1,5]}$, ocular myiasis ${ }^{[6,7]}$, genita ${ }^{[3]}$ and nasa ${ }^{[8]}$ had been documented. In most cases, unhygienic situations and other environmental factors promoted myiasis in most humid and dry zones of Nigeria. Other authors have reported on other aspects of myiasis dealing with cases where bodies were discovered late in houses ${ }^{[9]}$ and factors that promoted insects on carrions $^{[10,11]}$.

While some species included in this category, such as Phaenicia sericata, may frequently act as parasites for all or part of their larval development, more commonly, species in this classification are associated with dead tissues present in a wound and do not actually feed on living tissues. Another situation, termed "Pseudomyiasis or Accidental Myiasis," occurs when Dipteran larvae are accidentally ingested with food materials and pass through the digestive tract ${ }^{[12]}$. Their presence in the gut of the animal will often trigger various gastric problems. These infestations are not to be confused with the obligatory infestations of mammal digestive tracts by species in the subfamily Muscinae and Gasterophilinae.

Anthropophilic arthropods like cockroaches (Blattodea), silver fish (Thysanura), house flies (Diptera) and house and dust mites (Acari) have moved their habitat inside human dwellings to become part of the human biocenose ${ }^{[13-15]}$. These arthropods, however, do not directly depend on humans. Synanthropic insects like filth flies, biting midges, no-see-ums, punkies, mosquitoes (Diptera) feed off humans directly through blood sucking or off excrements and garbage produced by humans. Some of these insects have adopted an endophilic lifestyle entering our homes to feed and rest. Like some stored product pests, some of the hematophagous insect species have lost their natural or peridomestic habitat and have become entirely dependent on domestic harbourage and humans. Forensic implications can be found in any area of entomology or acarology associated with human habitation. Forensic entomology is receiving much attention ${ }^{[16]}$.

The distribution of myiasis is worldwide with more cases being reported from tropical, subtropical and warm temperate areas. However, the rapidity of international air travel and types of unhygienic wears and clothes transported permits this exotic tropical infestation to present in any region. Our focus for this study borders on neglect of the elderlies and associated infection with myiasis - causing flies. A close investigation and findings on the attraction of flies to living persons will call for care to the elderlies by both Government and individuals to offer basic needs and attention to the elderlies.

\section{Materials and Methods}

Ethical clearance was sought from the Department of Medical Laboratory Science of the Rivers State University of Science and Technology, Port Harcourt before commencing the study. Our sampling team was made up two health officers, four Post Graduate students of Medical Entomology and two academic researchers for each of the locations in the Niger Delta and South-east. Each personnel wore a white laboratory coat and was provided with pairs of hand gloves, facial masks, sterile instruments; forceps, spatula, cotton wools, glass Petri dishes and vials for the extraction of eggs and larvae before entering houses where abandoned elderlies were kept. Five samplers that were Final Year Entomology students of the Rivers State University of Science and Technology, Port Harcourt were used as samplers during the rainy season of 2014.

Our sampling was purposive and we sampled according to the number of people affected. During sampling, each abandoned victim was examined for eggs and larvae of dipterans [flies with a pair of wings]. Sampling was carried out weekly [7 am - 9 am] for one month depending on whether there were new reports or not, in cases of repeated infections, sampling continued and we obtained mean values on the eggs and/or larvae. Situations where we sampled just once did not have mean values and the results were presented as they were collected.

We assessed the infection rates of abandoned elderlies of two ecological zones in Nigeria [Niger Delta and South-East]. We studied a cohort of 5 - 10 patients presenting different cases of myiasis in elderlies within the age bracket 68 - 92 years. Larvae of different ages were extracted from different parts of the elderlies in the two ecological locations. Based on their sites of infection, five different types of myiases were diagnosed in the abandoned cases of the Niger Delta and South-East zones of Nigeria.

Number of cases sampled was recorded per location drawn from states of the two ecological zones; Niger Delta and SouthEast. The two zones were selected based on the fact that there were health issues on the presence of lesions and maggots in the skins of elderlies. The zones were different from each other; their terrains, humidity, temperature, rainfall and vegetation are not similar. On-site examinations / assessments were done and relations of the abandoned victims carried them into a screened canopy covered with mosquito nets to avoid flies from perching on the victims during the exercise. Skins of the victims were examined for boillike lesions and maggots where present were extracted using forceps after applying a drop of cholesterol- free oil. Antibiotics were applied to the opening to prevent infections.

\section{Sampling Procedure/Extraction}

Different parts of their body were examined and number of boil-like lesions [furuncles] was examined for myiasis-causing agents. Sample size was not definite as number sampled per locations depended on case[s] per village. At least we examined four cases in the Niger Delta and four cases in South-eastern States. We carried out a sampling plan that covered one month per location. Apart from age, the number of larvae extracted per furuncle was recorded.

\section{Extraction of Larvae}

In most rural areas of Nigeria, the first step that is usually taken is to drop palm oil into the furuncle and allow some seconds 
for the suffocating larva to wriggle up to the surface for air. It is usually at this point that the thumb and the first finger are placed around the furuncle and pressed [press as if one is pressing a pimple; administer just a little but firm pressure] to force the larva out. However in this study we applied a drop of cholesterol-free oil [Laser oil] which is not as heavy as palm oil but allows easier movement of the larvae within the cavity. Manual extraction was done with the aid of a pair of forceps. More than $94 \%$ of rural people interviewed in Niger Delta extracted maggots from the skin manually using their fingers ${ }^{[4]}$.

\section{Data Analyses}

Statistical analyses were performed using SPSS software. A-Z-test of means was used to determine whether the mean number of maggots collected differed significantly between the two ecological zones. Paired t-test was used to assess the significant difference between the numbers of larvae collected from the two zones. Pie charts were also used to show proportional distribution of data collected on the number of larvae in abandoned elderlies from the two zones of study. Correlation analysis was adopted to determine the relationship between number of larvae in the male and female elderlies, $t$-test was also used to assess whether larval distribution was higher in females than in males. Analysis of variance [ANOVA] was applied on the distribution of the developmental stages on elderlies In situations where there were significant differences between treatment combinations, Students' Newman Keule's [SNK] test, a furtherance of Duncan's Multiple Range Test [DMRT] was used to separate the means for a confirmation of significance.

\section{Results and Discussion}

Myiasis in abandoned elderlies was not a common occurrence in the Niger Delta region or elsewhere in Nigeria except in cases of contagious or infectious diseases and relations as it were showed behavior of neglect as they were mindful of contacting the disease. In Ughelli, we had a case of Tuberculosis and we could not collect samples. The door to the hut where the victim was kept was locked; only opened when food was pushed into the room. Sampling was hindered for the obvious reason of the samplers also endangering their own lives too. There also cases of aggressive HIV victims that threatened biting people; dipteran larvae were seen moving on the mats from the female victim's body, she died before our next attempt to sample. That was a case of neglect, no medical care and in addition to her aggression; people were scared going to her.

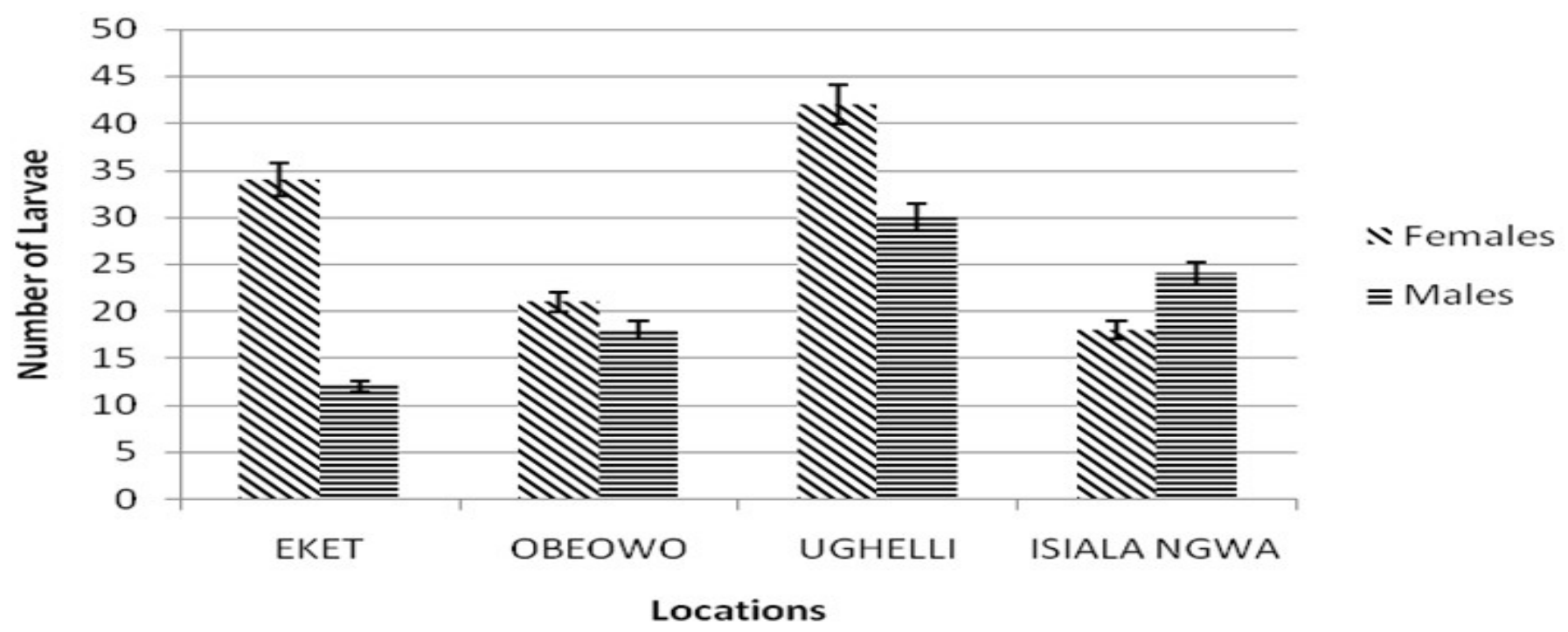

Figure 1: Distribution of C. anthropophaga in Abandoned Elderlies in the Niger Delta, 2014.

In most of the locations, female elderlies attracted higher numbers of fly larvae in the Niger Delta than the males [Figure. 1], in Ughelli there were significantly higher number of larvae extracted from females [SNK, $\mathrm{P}<0.05]$ and the number of larvae from Ughelli significantly differed from the number extracted from female elderlies from Eket in 2014 [SNK, P $<0.05$ ]. Higher incidences of myiasis in abandoned elderlies were obvious as the gravid female flies deposited their eggs on wounds, soiled cloths, mats and mattresses. Pupae were also collected as last instar larvae migrated under the mats, cloths and other beddings to pupate. In most cases, the presence of first instar larvae along with older larvae implied that apart from previous infections that gravid females were revisiting for more egg depositions on wounds. [Figure. 2] showed that in the South-east, the number of larvae extracted from female elderlies was significantly higher numbers than in males too. Significantly higher number of larvae $[>160]$ was extracted from the bodies of female elderlies from Ohaji, followed by those from Ogbaru [ $>120$ ] in South-east [D. M. R. T., S N K. P $<0.05]$. The terrain of Ogbaru was similar to the Niger Delta's with high environmental humidity and rainfall. The high humidity favoured the multiplication of myiasis agents and they preferred such environmental situations for ovi position and larval developments. Data collected from different parts of the body showed almost all parts of the body were affected [Figures 3 - 5]. In Eket, significantly higher number of larvae was extracted from the buttocks followed by those extracted from the groins. 


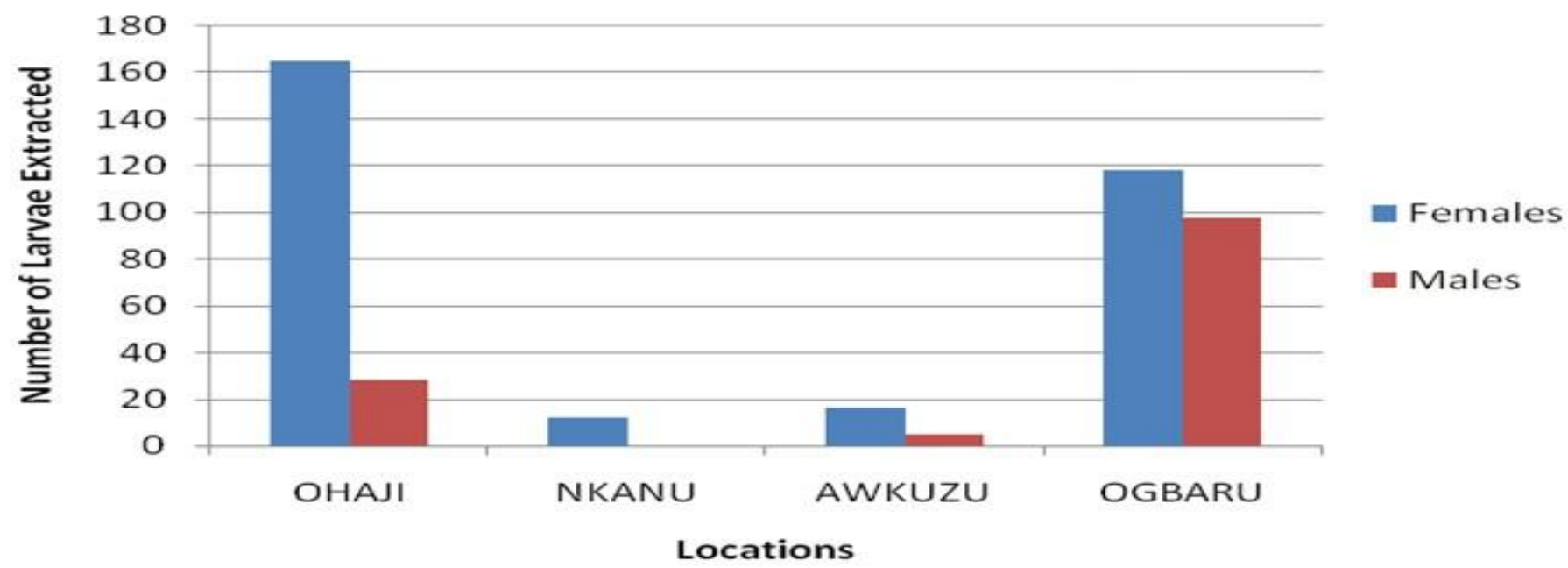

Figure 2: Distribution of Dipteran Larvae in Abandoned Elderlies in South-east Nigeria, 2014.

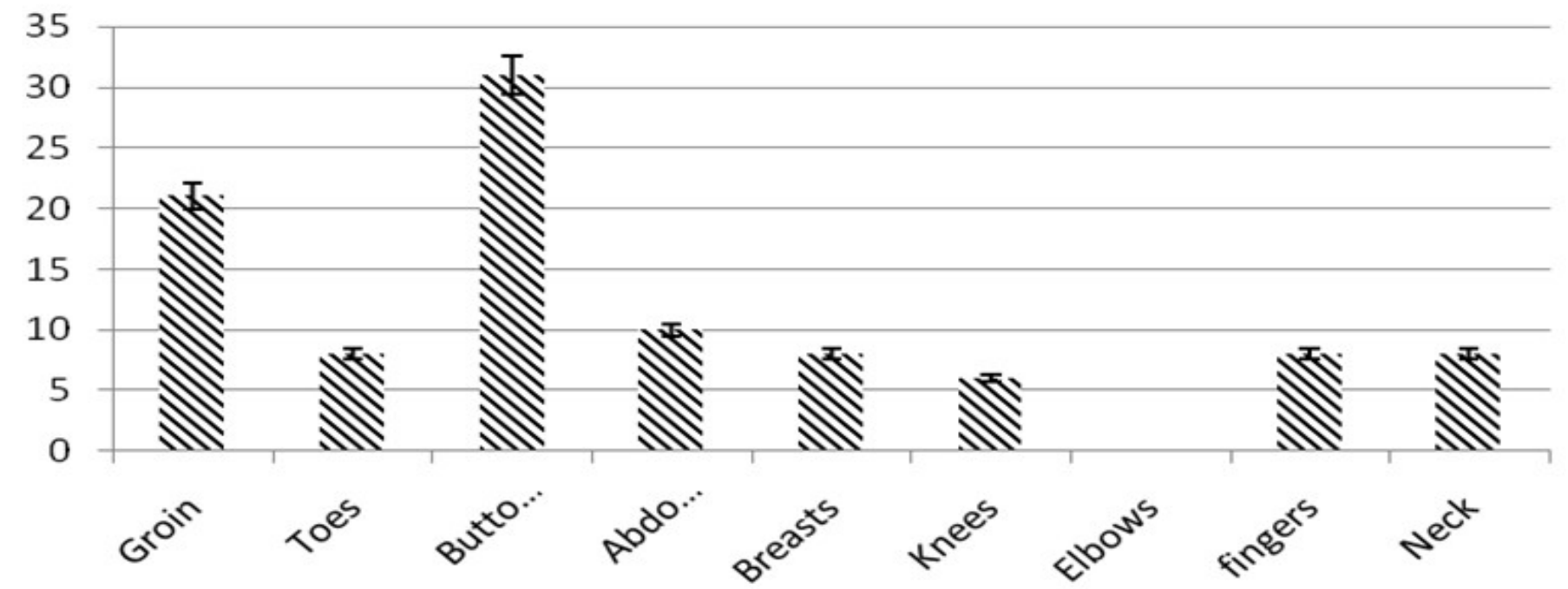

Figure 3: Distribution of C. anthropophaga on an Abandoned Female Elderly in Eket 2014.

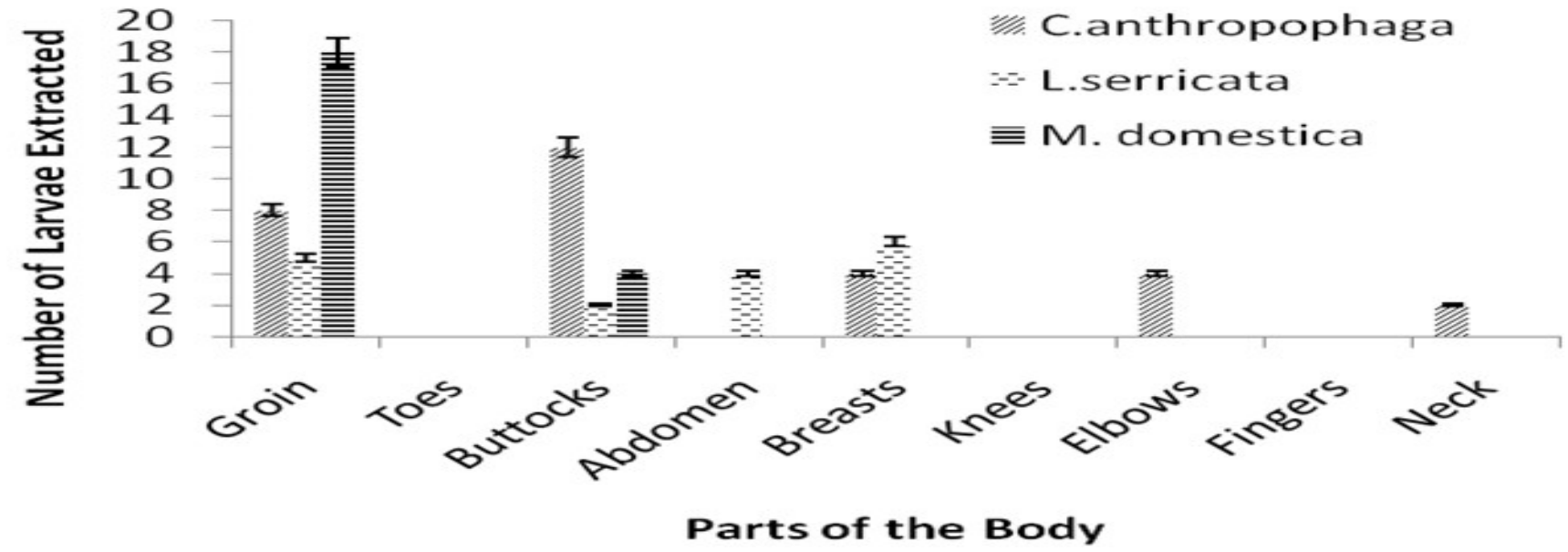

Figure 4: Distribution of Dipteran Larvae on an Abandoned Female Elderly in Obeowo, 2014. 


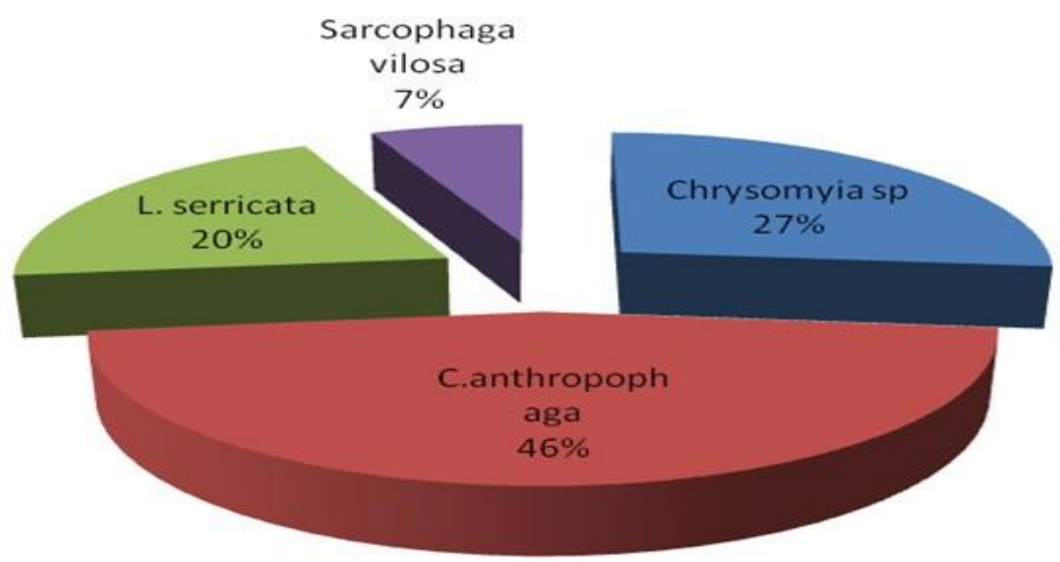

Figure 5: Distribution of Dipteran Larvae in Abandoned Elderly Males in Ogbaru, South East, 2014.

In Ogbaru town [Figure. 5] of South-east, another myiasis-causing fly, Chrysomia sp was extracted in male elderlies in the area. Dermatological data showed variations in infection rates of dipteran larval distributions in the abandoned elderlies of Ogbaru Town in South-east; prominent among them were C.anthropophaga 46\% [CI 24.5 - 46.3]; Chrysomia sp 27\% [CI 95\%, 18.3 - 27.3]; L. serricata 20\% [CI 95\%17.5 - 20.6] and Sarcophaga vilosa, 7\% [CI 5.3 - 7.4]. Percentage of C.anthropophaga extracted from the abandoned females was significantly higher than those of other larvae, an infection rate of C. anthropophaga was 40\% in Ughelli, [CI 95\%, 32.4 - 40.1]; 29\% infection by L. serricata [CI 95\%, 27.1 - 29.2]; Chrysomia sp 22\% [CI 95\%, 21.2 - 22.7] and infection rate of S. vilosa was significantly low [Figure. 6].

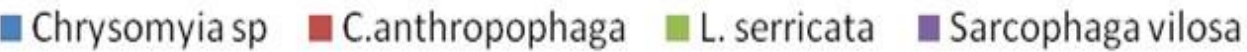

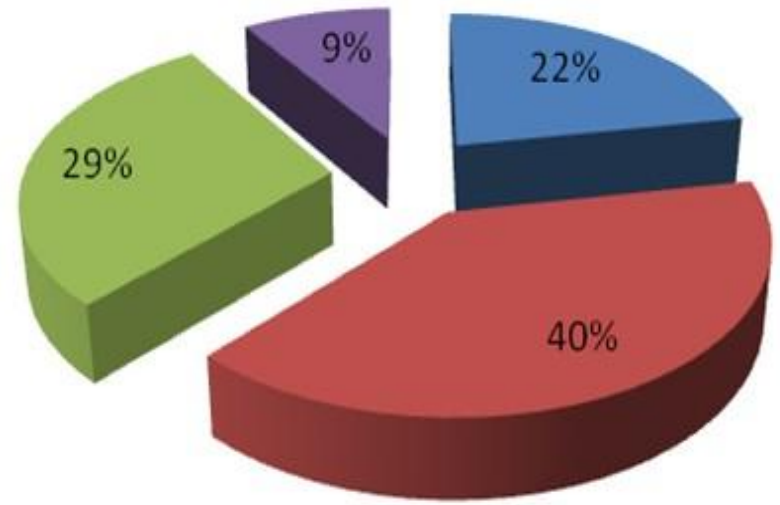

Figure 6: Distribution of Dipteran Larvae in Abandoned Female Elderlies of Ogbaru Town in South-east, 2014.

Generally abandoned elderlies harboured dipteran larvae of different stages that emerged as larvae from eggs deposited on different parts of their bodies. The decomposing portions of their bodies and the foul odour that accompanied it attracted the gravid females of the myiasis-causing flies. T-test at 5\% level of probability confirmed that the number of larvae from females' elderlies was significantly higher than those from the males. What was not easily discernible was the reason for higher attraction to females more than the males; the populations of dipteran larvae were higher in females from all the locations. The females' orifices might have contributed to this; as such areas oozed more fluids than in the males. The lack of personal hygiene could be the contributing factor for the cause of myiasis, and the vulva seemed a favorable site in unhygienic situations of rural women ${ }^{[3]}$. More so with the genital myiasis, Baidya [2009] also reported that female flies possibly are attracted by the fetid odor, and lay eggs in existing lesions. Thereafter, the larvae invade the tissue and feed themselves on living tissues. Genital prolapse could aggravate myiasis in the vaginal area causing oozing of fluids and subsequent infestation. Higher infestations affect physiological functions by destroying host tissues. Other authors ${ }^{[17-19,9,11]}$ documented the roles of insects' activities on abandoned elderlies and carrions. Lopez-Costa et al ${ }^{[20]}$, 2008 reported on myiasis of a severe complete uterine prolapse in an 89 year old woman. Wounds on the body of living persons should be attended to as they are potential targets to flies that live and feed on corpses at early stages of decomposition. In some rural settings in Nigeria, poverty is another factor apart from unhygienic situations that promotes myiasis and those in poverty stricken villages do not have financial aids or access to health centers. 
The number of $C$. anthropophaga was still higher in abandoned female elderlies in Ogbaru town of Anambra State, Southeast of Nigeria, 54\% [C I 95\%, 38.5 - 54.5]; following the warble fly population was that of Chrysomia sp, 26\% [C I 95\%, 17.4 26.3]; L. serricata 14\% [C I 95\% [13.2 - 14.5] and S.vilosa with its low record of 6\% [4.4 - 6.2] the elderlies of the other locations almost followed the same trend but with much lower populations of dipteran larvae in the bodies of abandoned elderlies.

In the Niger Delta, higher infection rates were higher in females than in males [Figures. 7 and 8]. Dermatological data of the myiasis in abandoned elderlies from the Niger Delta zone showed that infection rates were significantly higher in females than in males of Ughelli town [t-test ${ }_{0.95}, \mathrm{P}<0.05$ ]. Overall infection rates in abandoned females in Ughelli for the respective dipteran larvae were for C. anthropophaga 40\% [CI 95\%,36.7 - 44.6]; L. sericata, 29\% [CI 95\%, 27.5 - 30.3]; Chrysomia sp 22\% [C I 95\%, 20.5 - 22.8]; S. vilosa $9 \%$ [C I 95\%, 8.7 - 8. 8].

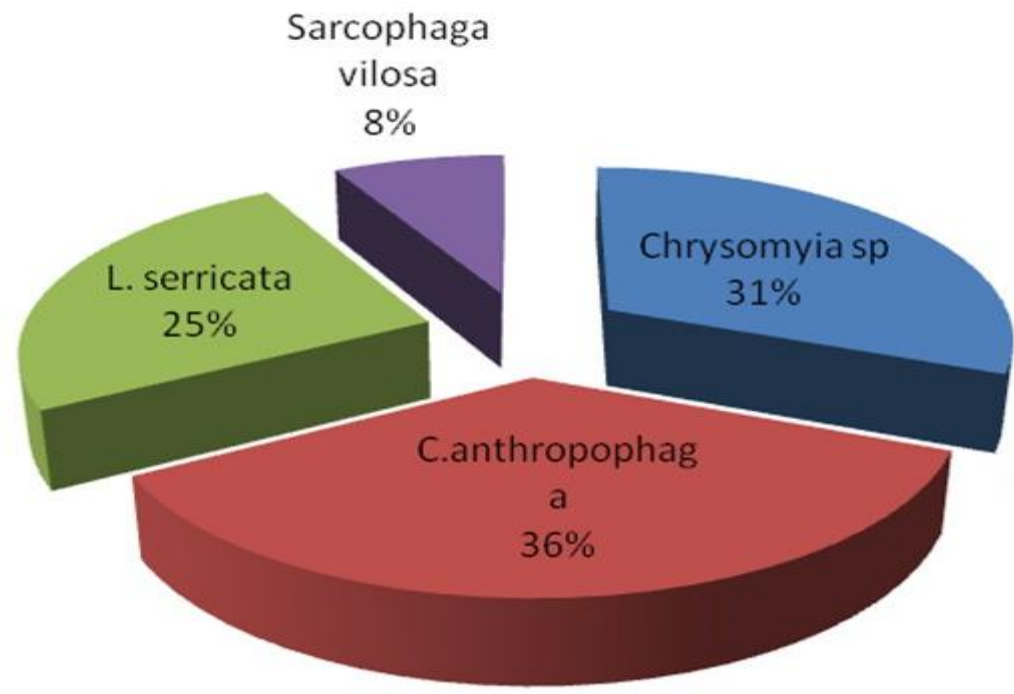

Figure 7: Males in Ughelli

\section{Chrysomyiasp $\quad$ C.anthropophaga $\quad$ L. serricata $\quad$ Sarcophaga vilosa}

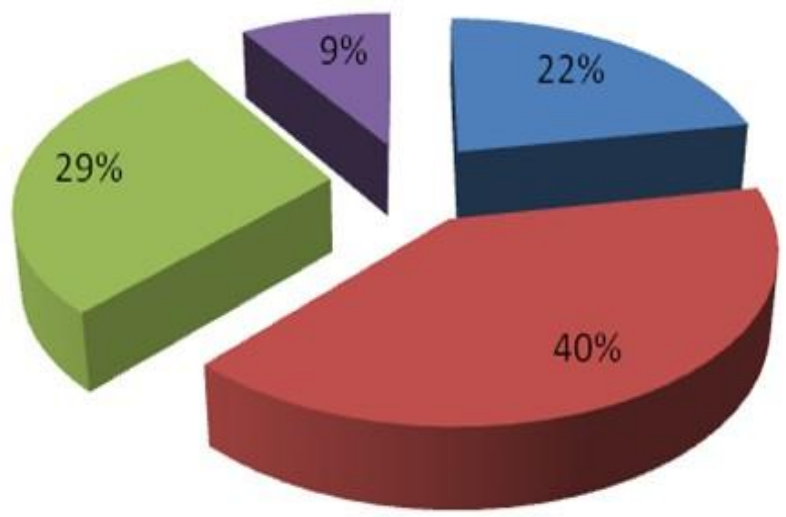

Figure 8: Females Ughelli

\section{Dermatological implications}

This included the perforations of the skins at various points and sites of infections that included stigmatizations and scars of myiasis wounds. Multiple myiases were found on skins of abandoned female elderlies that involved tunneling of larvae in search of necrotic parts of the elderlies' bodies for food. Neglect of elderlies is also a serious forensic case as it is regarded as a means of torture and could lead to death.

Neglect is a severe or persistent lack of attention to an elder's basic needs (such as adequate food, clothing, shelter, medical treatment, nursing care) that endangers or impairs the elder's health or safety. - Neglect also includes the lack of provision of medicine and auxiliary equipment according to medical advice, which causes physical harm to the elder. - If a formal service provider (e.g. Residential Care Homes for the Elderly, Integrated Home Care Services Teams, hospitals) fails to perform its caring responsibility and causes harm to the elder, the case can also be considered as neglect. Some elders were actually abandoned.

Abandonment is the act of neglecting or discarding an elder without justifiable reasons committed by a carer or guardian, 
which endangers or impairs the elder physically or psychologically. For example, a family member gives a wrong residential address to the hospital upon admission of the elder and makes it impossible for the hospital to contact him/her to discuss the medical and welfare issues of the elder.

\section{Conclusion}

Most situations of abandonment of the elderlies were observed to be higher where the victims had no children or where their children lived in the urban and neglected their old parents. It occurred in mostly low profile cases especially those stricken with poverty and in those with no financial obligations for medical care. Our data showed evidences of neglect of the elderlies in the two ecological zones of Nigeria and could lead to death; such intensities of neglect should be condemned.

\section{References}

1. Ogbalu, O.K., Achufusi, T.G., Adibe, C. The incidence of Multiple Myiasis in Breasts of rural nursing mother and oral infection in infants of the humid tropic, Niger Delta Nigeria. (2006) Int J Dermatol 45(9): 1069-1070.

2. Ogbalu, O.K. , Achufusi, T.G., Orlu, E.E. Epidemiology of human furuncular myiasis of Cordylobia anthropophaga (Grunberg) in Nigeria. (2013) Int J Dermatol 52(3): 331-336.

3. Ogbalu, O.K., Orlu, E.E., Wokem, G.N., et al. Factors Associated With The Prevalence Of Vulvar Myiasis Infection In Rural Nursing Mothers Of The Niger Delta, Nigeria. (2014) J Pharm Biol Sci 9(3): 81-87.

4. Ogbalu, O.K., Eze, C.N., BobManuel, R.B. A New Trend of Omphalitis Complicated with Myiasis in Neonates of the Niger Delta, Nigeria. (2016) Epidemiology (Sunnyvale) 6: 231.

5. Dogra, S.E., Mahajan, V.K. Oral myiasis caused by Musca domestica Larvae in a child. (2010) Int J Pediatric Otorhinolaryngol 5(3): 105-107.

6. Narayanan, S., Jayaprakash, K. Incidence of ocular myiasis due to infection with the larva of oestrus ovis (Oestridae Diptera). (1991) Indian J Ophthalmol 39(4):176-178.

7. Latif, I., Qamar, R.R., Attaullah, I., et al. Ocular myiasis. (2008) Pak J Ophthalmol 24(3): 151-153.

8. Ogbalu, O.K., Bob Manuel, R.B., Eze, C.N. Higher Incidences of Nasal Myiasis in Goats of the Niger Delta. (2016) [In Press]

9. Anderson, G.S. Factors that influence insect succession on carion. In: Byrd JH, Castner JL (eds) Forensic entomology: the utility of arthropods in legal investigations, 2nd edn. (2010) CRC, Boca Raton 201-250.

10. Anderson, G.S., Cervenka, V.J. Insects associated with the body: their use and analyses. In: Haglund WD, Sorg MH (eds). Advances in forensic taphonomy. (2002) CRC, Boca Raton 173-200.

11. Archer, M.S., Bassed, R.B., Briggs, C.A., et al. Social isolation and delayed discovery of bodies in houses: The value of forensic pathology anthropology, odontology and entomology in the medico-legal investigation. (2005) Forensic Sci Int 151(2-3): 259-265.

12. Shakeel, M., Khan, I., Ahmad, I., et al. Unusual Pseudomyiasis with Musca domestica Larvae in a trachaeostomy wound: a case report and literature review. (2013) Ear, Nose, Throat J 92(7): E38-E41.

13. Walter, D.E., Proctor, H.C. Mites - ecology, evolution and behaviour. (1999) CABI, Wallingford

14. Warner, A., Bostrom, S., Moller, C., et al. Mite fauna in the home and sensitivity to house-dust and storage mites. (1999) Allergy 54(7): 681-669.

15. Yoshikawa, M., Bennett, P.H. House dust mites in Columbus, Ohio, USA. (1979) Ohio J Sci 79(6): 280-282.

16. Byrd, J.H., Castner, J.L. Forensic entomology: the utility of arthropods in legal investigations, 2nd edn. (2010) CRC, Boca Raton.

17. Benecke, M., Josephi, E., Zweihoff, R. Neglect of the elderly: forensic entomology cases and considerations. (2004) Forensic Sci Int 146: S195-S199.

18. Goff, M.L, Charbonneau, S., Sullivan, W. Presence of fecal material in diapers as a potentiSal source of error in estimates of postmortem interval using arthropod development rates. (1991) J Forensic Sci 36(5):1603-1606.

19. Anderson, G.S. The use of insects in death investigations: an analysis of forensic entomology cases in British Columbia over a five year period. (1995) J Can Soc Forensic Sci 28(4): 277-292.

20. Lopes-Costa, P.V., dos Santos, A.R., Pereira- Fillho, J.D. et al. Myiasis in the Uterine Cavity of an Elderly Woman with a Complete Uterine Prolapse. (2008) Trans R Soc Trop Med Hyg 102(10): 1058-1060.

Online ISSN: $2381-0858$

Journal Title: Investigative Dermatology and Venereology Research Journal Short Name: Invest Dermatol Venereol Res
Ommega Online Publishers

E-mail: editor.dermatology@ommegaonline.org

Website: www.ommegaonline.org 